\title{
Laurent Bozard, «Mince de biens et povre de santé»: la «trilogie» médicale de Jean Marot
}

\section{Laura Ghiosso}

\section{(e) OpenEdition}

1 Journals

\section{Edizione digitale}

URL: http://journals.openedition.org/studifrancesi/34441

DOI: 10.4000/studifrancesi.34441

ISSN: 2421-5856

\section{Editore}

Rosenberg \& Sellier

\section{Edizione cartacea}

Data di pubblicazione: 1 novembre 2005

Paginazione: 395-396

ISSN: 0039-2944

\section{Notizia bibliografica digitale}

Laura Ghiosso, «Laurent Bozard, «Mince de biens et povre de santé»: la «trilogie» médicale de Jean Marot», Studi Francesi [Online], 146 (XLIX | II) | 2005, online dal 30 novembre 2015, consultato il 18 avril 2021. URL: http://journals.openedition.org/studifrancesi/34441 ; DOI: https://doi.org/10.4000/studifrancesi. 34441

Questo documento è stato generato automaticamente il 18 avril 2021.

\section{(c) (1)}

Studi Francesi è distribuita con Licenza Creative Commons Attribuzione - Non commerciale - Non opere derivate 4.0 Internazionale. 


\title{
Laurent Bozard, «Mince de biens et povre de santé»: la «trilogie» médicale de Jean Marot
}

\author{
Laura Ghiosso
}

\section{NOTIZIA}

LAURENT BOZARD, «Mince de biens et povre de santé»: la «trilogie» médicale de Jean Marot, in «Les lettres romanes», LVII, n. 1-2, 2003, pp. 19-32.

1 La «trilogie» qui fait l'objet de cette étude comprend trois œuvres de Jean Marot postérieures à la mort de la reine Anne de Bretagne. La perte de sa protectrice, outre que de son inspiratrice, mit le poète dans l'urgence de se procurer une charge; la Ballade de Maistre Jehan Marot présentée à Monsieur le Trésorier Robertet, le Quarantesixiesme Rondeau des Cinquante Rondeaux aussi bien que la Ballade à Monseigneur le duc de Vallois seraient autant de témoignages des appels de Jean Marot à la bienveillance de quelques probables bienfaiteurs. Si le thème dominant dans les Ballades et dans le Rondeau (le malheur du poète) aussi bien que l'appellation aux destinataires justifient une lecture en ce sens, l'Épitaphe de Triboulet, fol du roi Louis XII requiert un effort d'interprétation en tant qu'introduction. L'identification du personnage du fol et la datation de l'œuvre semblent autoriser le parallèle entre l'auteur et Triboulet, en tant que serviteurs loyaux qui, après avoir joui de la libéralité d'un souverain, sont tombés en misère. Par ce moyen, la «demande voilée» qui sous-tend aux vers de Marot fait appel au bon souvenir du roi Louis XII.

2 Venons-en à la nature «médicale» de l'analyse. Les deux Ballades sont bourrées de termes illustrant la métaphore du poète malade en tant que pauvre; les champs lexicaux relatifs à la maladie (les symptômes, le diagnostic, la thérapie) y sont tous exploités et les conditions du souffrant semblent de plus en plus désespérées. Ce développement détaillé légitime l'interrogation au sujet d'une correspondance avec 
l'état de santé de Jean Marot: pourquoi s'acharne-t-il à nous décrire son teint maladif et sa maigreur? Est-il vraiment malade?

3 Toute considération faite et sans dédaigner la consultation d'un médecin, M. Bozard aboutit, à travers une lecture soignée, à la réponse fournie par le poète même, dans ses vers; sa souffrance ne connaît qu'un remède, donné en termes clairs:l'argent. Egalement, c'est du manque d'argent que Jean Marot se plaint dans le rondeau En bon estat, où l'éloignement de la «croix» rappelle celui des pièces d'or, ainsi que la perte de sa situation le rend semblable à la fois à Job et à Adam, évoqués dans la Ballade au Duc de Vallois. Pas de doute: si l'argent est le remède, la pauvreté est la maladie. 